\title{
Las estructuras organizativas en la Provincia de Buenos Aires durante el gobierno de Cambiemos (2015-2019)
}

Organizational structures in Buenos Aires province under the Cambiemos government (2015-2019).

Ricardo Sebastián Piana Abogado. Dr. en Ciencia Política y Dr. en Ciencias Jurídicas. Universidad del Salvador. Universidad Católica de La Plata. ricardo.piana@usal.edu.ar

Daniel José Patiño Jaramillo Politólogo. Universidad Tecnológica de Bolívar.

danjoia108@gmail.com

Fecha de recepción:

19.8.20

Fecha de aceptación:

13.1.21

\section{Resumen:}

En este artículo se describe la política de estructuras organizativas de la Administración Pública de la provincia de Buenos Aires durante la gobernación de María Eugenia Vidal (2015-2019). El análisis de la legislación referida a los ministerios de Gobierno, de Jefatura de Gabinete/Coordinación y Gestión Pública, e Infraestructura y Servicios Públicos, y la evolución de las respectivas estructuras organizativas revela el crecimiento de esos organismos y el número de cargos políticos durante ese periodo a pesar del discurso oficial de recorte del gasto público, y la instalación de diseños institucionales anómalos. El análisis revela asimismo la existencia de rasgos organizativos y estilos particulares que diferencian a la gestión provincial de la desarrollada en el plano nacional por el gobierno de la coalición Cambiemos, a la que pertenece la ex gobernadora Vidal.

Palabras Clave: Provincia de Buenos Aires - estructuras organizativas - modernización administrativa - Cambiemos - María Eugenia Vidal 


\begin{abstract}
This article focuses on the organizational structure policy of Buenos Aires Province's Public Administration during María Eugenia Vidal's government (2015-2019). The analysis of policies, government statements and legislation on administrative reform and public employment related to the ministries of Government, Head of Cabinet/ Policy Coordination and Public Management as well of Infrastructure and Public Services, together with the evolution in their respective administrative structures, enables us to conclude that in spite of persistent government statements of public spending cuts, over the entire period there was an expansion on it in the above mentioned ministries as well the growth of political recruitment of public officers. Our analysis also discloses specific differences in provincial public management vis-à-vis the national government as performed by the electoral coalition Cambiemos -to wich former governor Vidal is affiliated.
\end{abstract}

Key-words: Buenos Aires Province - organic structuresadministrative modernization - Cambiemos - María Eugenia Vidal

\title{
1. Introducción
}

El Estado es un proyecto de organización política: la razón y la planificación son parte constitutiva de su esencia a diferencia de otras formas históricas donde el pragmatismo, la tradición o la impronta de una élite tuvieron un aspecto central. El Estado es producto de la modernización y en ese proyecto, su estructura organizativa es un eje central.

La consolidación de esta forma de organización política de la modernidad ha sido posible, entre otros factores, debido al doble proceso de concentración de funciones y división de tareas. Ese proceso, siempre en reestructuración, requiere de un aparato especializado para la recaudación, defensa, administración de justicia, ente otras funciones (Mayntz, 1985). Para desarrollar estas funciones complejas, el Estado ha debido organizarse y ha encontrado en la legalidad administrativa su nota distintiva (dominación legal-racional). Por ser un espacio político institucional de procesamiento y transacción legítima de conflictos (Vilas, 1997) el Estado puede ser estudiado a través de sus redes 
organizacionales, observando sus estructuras, que difieren en su capacidad política y legal para controlar recursos internos y externos, los aspectos presupuestarios, el personal que integra su estructura y los apoyos políticos que puedan existir.

Los cambios en la administración de los asuntos públicos suelen traer aparejados transformaciones normativas y organizativas que buscan legitimar su accionar, obtener recursos y viabilizar la implementación de nuevas políticas. Algunas modificaciones requieren cambios significativos en la estructura organizacional junto con la creación de nuevos roles y la desaparición de otros, la redesignación de áreas con otros nombres que expresen mejor los propósitos perseguidos e incluso la fusión o separación de distintos ámbitos de acuerdo con los intereses particulares del momento y del grupo político a cargo (Camou y Mateo, 2007).

En Latinoamérica, la reforma de la administración llevada adelante especialmente desde la década de 1990 ha implicado una verdadera reforma del Estado: el achicamiento y aplastamiento de la pirámide organizacional; recorte de sueldos y jubilaciones; privatizaciones y transferencias al sector privado han implicado, modificaciones con fuerte impacto el ámbito social, político y económico.

Se ha señalado que la Alianza Cambiemos forzó un giro hacia una reforma desde una línea de base cero: todo lo que no se hizo en previas gestiones gubernamentales permitía la corrupción, impedía el desarrollo y ahuyentaba las inversiones (García Delgado, 2019). El modelo de liderazgo político hipercentralizado con poco espacio para la discusión interna que el presidente Mauricio Macri impuso sobre la política también ha sido una nota del modelo Cambiemos. Sin embargo, y a pesar de la indudable pertenencia de María Eugenia Vidal a ese espacio y su adhesión a este núcleo duro ideológico, su gestión en la gobernación de la provincia de Buenos Aires no fue un mero espejo de la del ámbito nacional; fue un cuadro dentro de un cuadro, con notas propias y algunos visos de autonomía.

Precedido de un breve desarrollo del marco teórico necesario para la comprensión del proceso en estudio, en este trabajo queremos reconocer el especial rol que ha jugado la Provincia de Buenos Aires en el proceso de reforma estatal en los años de Cambiemos. Sin pretender hacer un listado de los procesos de reforma del Estado en el país en general y en la Provincia de Buenos Aires en particular, pretendemos hacer un breve recuento del contexto ideológico iniciado por el gobierno nacional de Cambiemos para dar cuenta de ese mismo proceso en la Provincia de Buenos Aires.

Nuestro estudio se detendrá en la estructura y los ejes de la reforma organizacional de la Administración Pública central bonaerense para lo cual se reconstruyó el andamiaje normativo a través de las leyes de Ministerio y especialmente los decretos de estructura de los Ministerios de Infraestructura y Servicios Públicos, de Gobierno, de Coordinación y Gestión Pública y de Jefatura de Gabinete de Ministros. Si bien ello supone un recorte 
a una estructura compleja, dado que el poder es quien moldea las instituciones, no encontramos mejor reflejo de ello que examinar el libre arbitrio del Ejecutivo en el diseño de sus propias estructuras. En efecto, el estudio a partir de las normas nos da un campo seguro y visible sobre el cual indagar, más aún cuando los Ministerios que estudiamos son centrales y claves para la gestión política y administrativa: los Ministerios de Infraestructura y Servicios Públicos, de Gobierno, de Coordinación y Gestión Pública y de Jefatura de Gabinete de Ministros, todos ellos han tenido un peso político propio e histórico en el devenir de la Administración Pública bonaerense.

Pretendemos informar si el discurso de reducción del aparato estatal se llevó acabo sobre las estructuras formales del aparato administrativo, tomando como base los organigramas aprobados por Decretos del Ejecutivo para los cargos correspondientes a los tres niveles inferiores al de Ministro, es decir, los relativos a Subsecretarios, Directores Provinciales Directores simples u otros cargos equiparados. ${ }^{1}$ Como señala Bernazza (2019:91), en Administraciones Públicas como las de Argentina la “... organización jerárquico vertical supone funciones decisorias en su vértice superior, un procesamiento tecno-administrativo en sus niveles intermedios y una tarea operativa en su base"; de allí que estudiar los entegramas y los cargos creados para cumplir las funciones del Estado puede ser una herramienta útil para dilucidar el proyecto de gobierno. La información se complementó con la realización de una entrevista semiestructurada a la funcionaria responsable del diseño de estructuras de la Provincia de Buenos Aires desde 2016 a 2019.

Por estas vías buscamos dar cuenta de la coherencia entre el eje discursivo y la praxis del gobierno provincial y resaltar las particularidades de la administración de María Eugenia Vidal respecto a las macro políticas producidas por el Ejecutivo Nacional.

\section{Las consignas post burocráticas en los años de Cambiemos}

El proceso de modernización, como parte de un plan de reformas más amplio, no es algo nuevo, ni deviene del gobierno de la alianza de Cambiemos (2015-2019). El aparato estatal argentino viene experimentando modificaciones y reformas desde principios del siglo pasado, pero es a mediados de la década de 1970 que la modernización comienza a recorrer un sendero de transformaciones basadas en un nuevo paradigma de Estado delineado por organismos multilaterales y corrientes neoliberales que luego serían enroladas en el Consenso de Washington.

Se entendió que la legitimidad del Estado no estaría dada por su estructura institucional sino por su capacidad de prestar bienes y servicios. Desde esta lógica, sería necesaria una administración con énfasis en los resultados y la satisfacción del usuario-cliente, lo que requeriría incorporar parámetros de medición de desempeño. Se sostuvo que pasando del control de los recursos y de los procesos propias de un esquema burocrático 
convencional a un nuevo criterio de control a través de evaluación de resultados, sería posible obtener políticas más eficaces.

Las consignas post burocráticas resultan sumamente atrayentes: su ejercicio conduciría a un gobierno más económico y eficiente, servicios de mayor calidad y programas más eficaces, ampliación del control político, mayor libertad a los gerentes públicos para que lleven a cabo su gestión y mayor transparencia gubernamental, postulados éstos de los que nadie podría renegar. Estos postulados parten de la crisis del Estado y la ineficiencia de la burocracia para solucionar los identificados como problemas de la gente.

Los discursos sobre la crisis del Estado han puesto su acento en las capacidades del Estado como organización: en su capacidad de operar una estructura grande y compleja; en su capacidad de tomar decisiones internas y en su capacidad de generar consensos para garantizar el tándem efectividad-legitimidad-estabilidad.

El estudio de las capacidades estatales ha dado lugar a una vasta literatura que informa, detecta y recomienda políticas, estructuras y acciones para superar déficits institucionales de la organización pública (Repetto, 2004; Bertranou, 2013; Bernazza y Longo, 2014). ${ }^{2}$ Uno de los puntos centrales en estos campos de estudio es el diseño del aparato organizativo: cómo las distintas áreas de decisión, en un contexto de división de tareas por especialización y control, deben coordinarse para tomar decisiones eficaces.

El gobierno de Mauricio Macri (2015-2019) hizo del discurso del crecimiento incontrolado del Estado "la "pesada herencia", un leit motiv en torno a la orientación de las políticas públicas, de la reforma administrativa y de los fines del Estado, ${ }^{3}$ proceso que ha sido identificado como “neoliberalismo tardío” (García Delgado y Gradin 2017).

El nuevo modelo de la denominada CEOcracia, ${ }^{4}$ no se esforzó mucho en diferenciarse de las consignas del New Public Management: en Argentina los gestores exitosos de las grandes empresas o grupos económicos locales, pasaron a integrar a fines del 2015 lo que se autodenominó como mejor equipo ministerial de los últimos cincuenta años. Tal vez, el cambio más notorio fue el fuerte discurso en torno al optimismo, las emociones, las redes sociales y una visión de la psicopolítica exacerbada de individualismo (Han, 2014) que contrasta con los argumentos racionalistas o de cálculo de la eficiencia del discurso de los noventa.

En el aspecto institucional, el legado de Cambiemos ha sido pobre (Cao, Laguado Duca y Rey, 2018; Anria y Vommaro, 2020; García Delgado, 2020). Sin embargo, se ha señalado también que aún cuando no se hayan llevado a cabo grandes modificaciones en los aspectos legales e institucionales, Cambiemos trabajó sobre los valores, convicciones e intereses (Bernazza, 2019; Canelo, 2019): desde la posverdad, la positividad y la meritocracia fue construyendo un discurso que exaltó la individualidad y la prescindencia del Estado. Por 
el otro lado, el fantasma de la corrupción y la opacidad del Estado y su ineficiente burocracia fueron una punta de lanza para las políticas modernizadoras. En efecto, la burocracia entendida como obstáculo a las iniciativas de inversión del mercado, sobre todo el externo, fue uno de los principales ataques del gobierno que asumió en 2015. Cambiemos orientó las políticas públicas de reforma administrativa al expediente digital, los sistemas biométricos de control de asistencia, el retiro voluntario, la flexibilización o simplificación de procedimientos y la contratación de personal bajo modalidades precarias en el marco de un fuerte discurso desburocratizador. De acuerdo a Astarita

Cambiemos considera que su papel es vital para reimpulsar el ciclo económico, y que la maquinaria estatal, tal como se encuentra configurada en la actualidad, constituye un escollo que inhibe la iniciativa privada y la inversión. Por ende, el Estado debe reducir al mínimo indispensable sus intervenciones y mantener sólo aquellas que estén destinadas a potenciar la acumulación. Tal concepción queda plasmada en una serie de medidas de política económica y, a la vez, en el discurso utilizado para justificarlas, en el que se hace énfasis en los aspectos negativos del aparato estatal (déficit fiscal, inflación, presión tributaria, burocracia (2018:62).

La modernización de Cambiemos buscó la reinserción de Argentina en el mundo, la introducción de las lógicas exitosas del ámbito privado en la gestión de lo público y la ruptura de las negociaciones sectoriales en las políticas públicas por un modelo de decisión centralizado. Muchas de estas políticas ya habían sido implementadas en el gobierno de la Ciudad Autónoma de Buenos Aires por el PRO, y fueron trasladadas a la Nación y a la Provincia en un proceso de mimetismo institucional inédito en nuestro país (Bernazza, 2019).

Investigadores afiliados al Centro de Implementación de Políticas Públicas para la Equidad y el Crecimiento (CIPPEC) destacan la variación y el crecimiento que tuvo el tamaño de la Administración Pública Nacional en el período 2015-2019: en el primer año de Cambiemos hubo un crecimiento en los distintos niveles del aparato burocrático administrativo: "ministerios (de 18 a 23), secretarías (de 69 a 85), subsecretarías (de 165 a 204), direcciones nacionales (de 290 a 398) y direcciones generales (de 127 a 144)", tendencia que continuó en 2017 al punto de alcanzar el máximo histórico desde el regreso a la democracia y que, a pesar del recorte de 2018 en el contexto de la crisis cambiaria de abrilmayo de ese año, terminó siendo aún más grande que el de 2015 (Gasparin et al., 2020).5

Las investigaciones han privilegiado el seguimiento y la evolución de las estructuras nacionales. Como hemos señalado más arriba, es muy poco lo que se ha estudiado en los ámbitos provinciales, dándose por supuesto que los ámbitos subnacionales con 
gobiernos de Cambiemos reprodujeron el esquema nacional. En la sección siguiente se indaga qué tomó la gestión provincial del modelo nacional: ¿̇tuvo un modelo propio o sólo replicó las consignas que se desplegaban desde el discurso nacional?

\section{Aspectos generales de la gestión de Vidal}

La asunción de María Eugenia Vidal cerró un ciclo de hegemonía ininterrumpida del Partido Justicialista en la Provincia de Buenos Aires desde el año 1987. Pero este proceso, sin lugar a dudas, ha sido excepcional: la llegada de Cambiemos, con un modelo de liderazgo de empresa familiar ejercido por el PRO en forma simultánea en el nivel nacional, en la Ciudad Autónoma de Buenos Aires, en la Provincia de Buenos Aires y en muchos de los grandes municipios bonaerenses brindó la oportunidad para llevar adelante un proceso inédito de reformas institucionales convergentes top-down. ${ }^{6}$

El mimetismo institucional con la gestión de la Ciudad Autónoma de Buenos Aires fue evidente y varias de esas reformas se mantienen vigentes. Ejemplos de este "traspaso" de políticas, lo encontramos en el sistema de compras, de Buenos Aires Compra (BAC) a Provincia Buenos Aires Compra (PBAC), Sistema de Gestión de Administración Financiera (Fiscante y Piana, 2018), los contratos de servicios sustitutivos del empleo público o los retiros anticipados o voluntarios fueron comunes a la Provincia, Nación y Ciudad de Buenos Aires; las políticas de Atención Ciudadana tomaron como eje la creación de espacios institucionales; el concepto de "vecino" porteño al "vecino" de un territorio no totalmente urbano, como la Provincia de Buenos Aires, el modelo del SAME, el Triage en los hospitales, el Metrobus, cual franchising de políticas públicas y otras reproducciones estéticas de la ciudad de Buenos Aires al Conurbano que ampliaron los "no lugares" de la Ciudad hacia el Conurbano.

En marzo 2016 el Presidente Macri aprobó por Decreto $N^{\circ}$ 434/16 el Plan de Modernización del Estado cuyos ejes eran: 1) Plan de Tecnología y Gobierno Digital;2) Gestión Integral de los Recursos Humanos; 3) Gestión por Resultados y Compromisos Públicos; 4) Gobierno Abierto e Innovación Pública; 5) Estrategia País Digital. En julio de 2016, impulsado por el Poder Ejecutivo provincial, la Legislatura bonaerense aprobó el Plan Estratégico de Modernización de la Administración Pública de la Provincia de Buenos Aires, Ley $\mathrm{N}^{\circ} 14.828$, destacándose en los fundamentos, que el proyecto

responde a la imperiosa necesidad de adecuar los procesos administrativos a los sistemas de calidad, herramientas informáticas y buenas prácticas de gestión administrativa actualmente vigentes a nivel regional y mundial".?

En febrero 2016 la gobernadora Vidal aprobó el régimen de las declaraciones juradas patrimoniales de los funcionarios y agentes del Poder Ejecutivo, extendiéndose por 
Decreto $N^{\circ} 407 / 17$ al personal policial con jerarquía superior a Subcomisario. Esta norma seguía el modelo de Declaraciones Juradas implementadas por la Ley de Ética Pública de la Ciudad, Ley $N^{\circ}$ 4.895. Finalmente, desde el Ejecutivo Nacional, por Decreto No 258/19, se aprobó el Plan Nacional Anticorrupción 2019-2023. ${ }^{8}$

En materia de empleo público distintas políticas de reducción de la planta pueden detectarse, tales como el Régimen de Retiro Voluntario, la suspensión, por un año, de las designaciones de personal de planta, control biométrico junto con políticas salariales por debajo de la inflación (Gil García y Piana, 2019).

Por otro lado aparecen, ya sea con módulos ad hoc o contratados, coordinadores y Project Managers por fuera de cualquier estructura, en muchos casos con salarios equiparados o superiores a los correspondientes al nivel de Director, sin responsabilidad de firma pero con evidente pretensión disruptiva de la lógica del empleo y el funcionario público (Bernazza, 2019).9

En materia administrativa, las delegaciones acordadas a los Ministros fueron crecientes, llegando a incluir la designación de los funcionarios para estructuras orgánicofuncionales aprobadas por Decreto del Poder Ejecutivo, con excepción del cargo de Subsecretario o rango equivalente (véase Decreto $N^{\circ} 230 / 16$ y luego Decreto $N^{\circ}$ 272/17). Estas delegaciones también fueron crecientes en materia de contrataciones, cuando el Ejecutivo provincial reglamentó, a través del Decreto $N^{\circ} 1.300 / 16$, la Ley de Compras aprobada durante el mandato del entonces gobernador Daniel Scioli (Ley $\mathrm{N}^{\circ}$ 13.981de la PBA). Por esta reglamentación sólo requerirían intervención de la máxima autoridad de la Provincia en los procesos licitatorios de más de 15.000.000 Unidades de Contrataciones, valor que al final del mandato tenían un valor de $\$ 50$ cada una. $^{10}$

En materia de reformas tecnológicas, el proceso tuvo vaivenes. Según Badía y Saudino (2019)

Las marchas y contramarchas en la conformación organizativa de la Subsecretaría [de Modernización] podrían reflejar que no existía en el inicio del gobierno una estrategia de modernización clara y unificada. Quizás también eso explique que al comienzo de la gestión prácticamente se replicaran las medidas implementadas en la Ciudad Autónoma de Buenos Aires (CABA) y en el gobierno nacional, medidas que luego fueron reevaluadas a la luz de la situación provincial y forzaron cambios en los ejes de la política de modernización.

La Ley de modernización propiciada por Cambiemos en Provincia, aprobada como Ley $\mathrm{N}^{\circ}$ 14.828, introdujo un proyecto de reforma del Estado donde claramente la 
tecnología juega un rol central. Además, de la lectura de los ejes del Plan Estratégico de Modernización de la Administración Pública de la Provincia de Buenos Aires, se advierte que los programas, normas y procedimientos buscaron implantar un nuevo modelo de gestión de los recursos públicos sustentado en la planificación y el control, en el proceso de reforma de los sistemas administrativos orientados a los resultados, a la transparencia y el control ciudadano en la gestión pública. Badía y Saudino también señalan que, a pesar de las continuidades en materia de modernización que se han dado en la provincia, el gobierno provincial de Cambiemos "ha tendido a invisibilizar las iniciativas de modernización del Estado de las gestiones anteriores en el marco de una narrativa de carácter "refundacional" que lo ha caracterizado" (2019) y agregan que una de las notas del modelo Cambiemos en la Provincia fueron las intervenciones "fuertes y rápidas", de alto impacto en un contexto organizacional que evaluó como resistente respecto a cualquier tipo de cambio.

\section{Dimensión discursiva}

La desconfianza de los elencos políticos a las burocracias heredadas, tanto en lo que refiere a sus capacidades técnicas como a su lealtad para ejecutar las tareas encomendadas, es un fenómeno extendido que se profundiza cuanto mayor es el cambio del signo político con el de la gestión anterior (Thwaites-Rey, 2005; Oszlak,.2009). Pero en el caso, además de haberse cuestionado la eficacia de la burocracia mediante la introducción de nuevos agentes superpuestos (aunque precarizados) y el achatamiento salarial de las plantas estables, se construyó un discurso en torno al tamaño y las funciones del Estado como problema.

Para esta definición crítica del Estado, que es político-ideológica (Tamayo Saez, 1997), se fue construyendo la necesidad de achicar las estructuras. Un factor clave en todo proceso de reforma es un discurso claro y fuerte, no sólo en el nivel técnico sino, especialmente, en el máximo nivel político. Por ello haremos un repaso por las justificaciones de los principales actos y los discursos públicos de la gobernadora Vidal durante el acto de asunción y en las aperturas de sesiones legislativas.

La funcionaria sostuvo de manera reiterada desde el inicio de su gestión, que tenía como uno de sus objetivos reducir el gasto político de la provincia mediante una reducción de cargos y así presentaba su primera Ley de Ministerios. ${ }^{11}$ Pretendía, desde ese momento, diferenciarse del Presidente Macri quien había aprobado una estructura organizativa inicial con veinte ministerios y tres Secretarías (http://servicios.infoleg. gob.ar/infolegInternet/anexos/255000-259999/256606/norma.htm). Afirmó que el criterio rector habría de ser la austeridad; todo lo que se ahorrara debía servir de puntapié para inversión en políticas públicas de infraestructura escolar, hospitalaria, obras de cloacas y aguas potables. Y señalaba:

... creo que hay un espacio para optimizar gastos, como la reducción del gasto político. 
-¿Qué tipo de gasto político?

-Los recursos que se destinan a cargos políticos, entre asesores y funcionarios. Creo que se puede hacer un equipo más chico, más funcional, y que esté comprometido todos los días con la tarea...

(La Nación, 2015 https://www.lanacion.com.ar/ politica/maria-eugenia-vidal-hay-que-reducir-elgasto-politico-en-la-provincia-nid1853817).

Los fundamentos de leyes sobre Reforma del Estado y la Administración impulsados durante la gestión de Vidal pusieron el foco en la crisis del Estado bonaerense. Así, la Ley de emergencia en materia de infraestructura y servicios públicos se fundamentaba desde el Poder Ejecutivo en

La necesidad de realizar con la mayor premura posible obras de infraestructura y servicios públicos (saneamiento, viales, hídricas, edilicias, etcétera) resulta de toda evidencia. Esta situación crítica justifica la adopción de un conjunto de medidas tendientes a agilizar los procedimientos administrativos que confluyen a dar respuesta a la misma (Fundamentos del proyecto de ley remitido por la Gobernación a la Legislatura).

En tanto, la Ley $N^{\circ} 14.815$ de emergencia administrativa y tecnológica se fundamentó por el Ejecutivo en que

... la función administrativa -entendida como aquella actividad permanente, concreta y práctica del Estado que tiende a la satisfacción inmediata de las necesidades del grupo social $y$ de los individuos que lo integran- no puede interrumpirse, siendo necesario declarar la emergencia y adoptar medidas de excepción tendientes a facilitar el funcionamiento y a propiciar el rápido reordenamiento del Estado.(...)Por otra parte, con la declaración de emergencia tecnológica se procura lograr el fortalecimiento y modernización de todos los organismos públicos provinciales y la consecuente agilización de los procedimientos administrativos, lo que se traduce en soluciones eficaces, eficientes y oportunas para todos los ciudadanos de la Provincia (Fundamentos de la Ley $N^{\circ} 14.815$ ). 
Además, en su artículo $1^{\circ}$ declaraba la emergencia con un insólito manifiesto político que señalaba su necesidad

... con la finalidad de paliar el grave déficit en estas materias [administrativa y tecnológica] que en el transcurso de los últimos años se ha visto incrementado progresivamente y posibilitar la realización de las acciones tendientes al fortalecimiento y modernización tecnológica de los organismos públicos provinciales para cumplir así con el mandato constitucional de promover el bienestar general (Fundamentos de la Ley $\mathrm{N}^{\circ} 14.815$ ).

Finalmente, destacamos lo señalado en la Ley No 14.828 aprobó el Plan Estratégico de Modernización de la Administración Pública, que responde a

la imperiosa necesidad de adecuar los procesos administrativos a los sistemas de calidad, herramientas informáticas y buenas prácticas de gestión administrativa (Ley $\mathrm{N}^{0}$ 14.828).

Hemos señalado en otro lugar que a través de los objetivos a alcanzar y sus principios rectores, leídos como metas no alcanzadas, se infiere de la lectura de la Ley: falta planificación, ausencia de control y previsión de resultados; opacidad, despilfarro, irracionalidad, ineficiencia, ineficacia, obsolescencia, corrupción, inequidad, descoordinación, etc.

Esta estrategia discursiva como soporte justificatorio de un modelo estatal aparece también de una forma clara e insistente en las presentaciones del Ejecutivo ante la Legislatura provincial. En el discurso de asunción de mando, el 10 de diciembre de 2015 Vidal ya pretendía instalar la idea de haber recibido una Provincia quebrada y en tal sentido expresaba:

... nos duele mucho a todos el abandono que sufre la Provincia, en lo que respecta a la economía, recibimos una Provincia quebrada, deficitaria, llena de deudas, incluso en las áreas más sensibles, pero la mayor deuda es con los vecinos, porque la ausencia del Estado en muchos lugares es grave. https://www.youtube.com/watch?v=2VdNeAFpSeA (minuto 31:02 a 31:23)

En el discurso de apertura de sesiones de 2016 Vidal habló a sus vecinos (sic) desde el contexto de una Provincia quebrada (minuto 6:25) donde se "redujeron un 30\% los cargos políticos" (minuto 6:36).Y afirmaba (minuto 10:37): 
... tenemos que superar las dolencias de un Estado que no puede dar respuestas, tenemos que lograr un Estado con menos egoísmo y más vocación pública, un Estado moderno que esté a la altura del Siglo XXI, un Estado que deje de emparchar de manera mediocre los problemas $y$ planifique, invierta y genere oportunidades para todos, un estado justo $y$ transparente (...)

(https://www.youtube.com/watch?v=GmbCKVIVA0A).

Refirió más adelante a un "Estado obsoleto en términos administrativos y deuda social enorme" (minuto 14), un Estado que está más preparado para obstaculizar que para gobernar, con un sistema de administración lento y burocrático, sin ningún proceso 100\% digital. Vidal asume un liderazgo vocacional, de cuasi sacrificio: "No estoy acá para construir una candidatura o hacerme rica" (minuto 15:27). E insiste: "recibimos un Estado que no puede dar respuesta a los problemas porque una licitación para hacer una obra lleva entre nueve $y$ once meses, solo para adjudicarse" (minuto 21:20 a 21:32).

En 2018, el discurso de apertura de sesiones insistió con el sueño de un Estado moderno asociado con la digitalización y la rapidez; para que los trámites puedan hacerse desde las casas y no haya que acercarse a las oficinas públicas o las comisarías. Reaparece la idea del vecino lejos del Estado (minuto 19:12 hasta 19:48). https://www.youtube.com/watch?v=T7wIA6Ckef8

En 2019, el que iba a ser su último discurso de apertura de sesiones, señaló:

Pasamos de un Estado obsoleto, lento y burocrático, a uno que empieza a dar respuestas, pasamos de 175 mil expedientes por año a tenerlos digitalizados, modernizar la administración, no solo es que sea más ágil y accesible a los ciudadanos, también es que sea más transparente, el próximo gobierno va a encontrar un Estado con cuentas ordenadas, capacidad para invertir, e información pública que sirva para trazar objetivos a largo plazo (https://www.youtube.com/watch? $={ }_{\mathrm{cRuKdW}} 11 \mathrm{Bvo}$ (min. 52:04)

\section{Las leyes de ministerios}

La primer ley de ministerios de la gestión en el gobierno de María Eugenia Vidal fue la $\mathrm{N}^{\circ}$ 14.803,promulgada el 10 de diciembre de 2015 y publicada el 14 de diciembre de 2015 que contemplaba originalmente once carteras ministeriales y 6 Secretarías, ${ }^{12}$ incluyendo los ministerios de Gobierno y de Infraestructura y Servicios Públicos y el 
Ministerio de Coordinación y Gestión Pública que fuera posteriormente suprimido y reemplazado por el Ministerio de Jefatura de Gabinete. A esto debe sumársele la Dirección General de Cultura y Educación, que funge como Ministerio de Educación y que, por ser un órgano creado por la propia Constitución cuyo cargo requiere acuerdo del Senado, suele estar regulado en ley independiente a la de ministerios. ${ }^{13}$

Dicha ley señalaba en sus fundamentos "la necesidad de optimizar la organización de la Administración Pública a fin de contribuir al logro de una mayor eficiencia"; conforme a dicha estrategia institucional propuso la fusión del Ministerio de Infraestructura y la Secretaría de Servicios Públicos, así como la eliminación del Ministerio de Jefatura de Gabinete creado durante la gestión de Daniel Scioli. ${ }^{14}$ La creación del Ministerio de Coordinación y Gestión Pública fungía, sin embargo, como Jefatura de Gabinete pues todos los decretos, cualquiera fuere el área, deberían tener su refrenda (art. $5^{\circ}$ Ley $\mathrm{N}^{\circ} 14.803$ ).

Contrariamente a sus promesas electorales, la gestión de Cambiemos significó la incorporación masiva de CEOs en aéreas de dirección y gerenciamiento del Estado que, de acuerdo a García Delgado (2019) provocó “una verdadera repartija de ministerios”. En la provincia de Buenos Aires, con la excepción de los ministros de Asuntos Agrarios (Leonardo Sarquís) y de Trabajo (Marcelo Villegas) las primeras líneas políticas provinieron de la Ciudad Autónoma de Buenos Aires con alguna experiencia en la gestión local. ${ }^{15}$

La ley de ministerios tuvo varias modificaciones a lo largo de su vigencia: a pocos días de asumir y aprobar su primera Ley, el 16 de enero de 2016 se sancionó la Ley N ${ }^{\circ}$ 14.805, que cambiaba la denominación del Ministerio de Asuntos Agrarios por Ministerio de Agroindustria, otorgó más poder al Ministro de Coordinación y Gestión Pública, que ahora debía refrendar los actos de los Secretarios y se la quitó al Ministro de Gobierno, e incorporó funciones al Ministerio de Infraestructura. Asimismo creó el Organismo de Provincial de Niñez y Adolescencia como entidad autárquica, en la órbita del Ministerio de Desarrollo Social. No mucho tiempo después, (mayo 2016) la Ley N 14.815 de Declaración de la Emergencia Administrativa y Tecnológica, introdujo cambios en las competencias de algunos ministerios que denotan otra lógica de poder entre los actores. ${ }^{16}$ El 19 de agosto de 2016, la Ley N 14.832 cambió la denominación del Ministerio de Producción, Ciencia y Tecnología, por Ministerio de Producción y a su vez se incorporaron al Ministerio de Ciencia, Tecnología e Innovación y el Ministerio de Gestión Cultural, eliminado consecuentemente la Secretaría de Cultura. ${ }^{17}$.

A fines de 2017 al propiciar la que iba a serla última Ley de Ministerios de su gestión,la № 14.989 (https://normas.gba.gob.ar/documentos/BKaAKuo0.html)Vidal señaló que se preveía la eliminación de 221 cargos políticos: 14 subsecretarías de 80 existentes en ese momento, 82 direcciones provinciales de 277 y 125 direcciones de 633 existentes en ese entonces (https://www. elpatagonico.com/maria-eugenia-vidal-envia-proyecto-reducir-221-cargos-n3053267). 
El Ministro Federico Salvai, por entonces Jefe de Gabinete y hombre de extrema confianza de la Gobernadora, justificó el recorte en una reunión de gabinete ampliado y sostuvo que "no se afecta la planta permanente ni es en contra de los trabajadores de la administración central. Lo que buscamos es una nueva estructura para fortalecer la gestión, con responsabilidades claras y tener un gobierno mucho más ágil” https://www.latecla. info/5/87457-el-tijeretazo-221-cargos-polticos-menos-secretaras-que-

En verdad, dicha reducción iba a depender de los decretos de estructura que con posterioridad se dictaran. Sin embargo, habiendo iniciado con once ministerios y seis Secretarías, la gestión Vidal finalizaba con catorce Ministerios y cuatro Secretarías. Esas cifras respondían a la necesidad de empalmar con las medidas que, para esa fecha, se anunciaban desde el gobierno nacional, que buscaban reducir la estructura entre un 15 y un 20 por ciento, luego de haber aumentado los Ministerios de la Administración Pública Nacional a 22 en enero de 2017, reducción en la Nación que no llegó sino hasta la crisis de septiembre de 2018 cuando los redujo a diez.

En el Anexo 1 figura la lista de Ministerios durante la gestión de Vidal, tomando como base la última ley del periodo de Scioli; se advierte que el recorte anunciado no tuvo lugar y que, al contrario, aumentó la cantidad de ministerios.

Queda por señalar otra diferencia respecto al Ejecutivo Nacional: si bien hubo algunas modificaciones en las estructuras de los Ministerios, desde 2018 y hasta el final de su gestión, Vidal ya no modificaría su Ley de Ministerios prescindiendo del ritmo frenético de la Nación. Sólo acompañaría el discurso presidencial acerca de la necesidad de reducir el gasto para reorientarlo en obras: en febrero de 2018 en un discurso junto al Presidente Macri justificó los recortes señalando que era necesario "sacar la plata de donde nunca llega a la gente" y ponerla en obras (https://www.cronista.com/economiapolitica/Juntoa-Vidal-Macri-defendio-la-reduccion-de-cargos-en-el-Estado-20180201-0083.html)

\section{Los decretos de estructura en los Ministerios seleccionados}

Previo al inicio del análisis de los decretos de estructura de los Ministerios seleccionados, corresponde destacar que uno de los primeros actos de la gestión de Vidal fue derogar, sin fundamentación alguna, por Decreto $N^{\circ} 37 / 15 \mathrm{~B}$, el Decreto $N^{\circ}$ 1.322/05 de diseño de las estructuras del Estado Provincial. Este decreto creaba un instructivo para guiar el diseño de estructuras orgánico funcionales en todo el ámbito de la Administración Pública Provincial, centralizada y descentralizada. Debe reconocerse sin embargo que en casi todos los decretos de las gestiones de Felipe Solá y Daniel Scioli las estructuras aprobadas contenían alguna excepción al Decreto $N^{\circ} 1.322 / 05$, esas desviaciones marcaban la pauta de la politicidad de la estructura aprobada medida sobre la base de cuánto se había desviado respecto del Decreto (vid anexos 2 a 4). 
Ya sin limitación alguna, en términos generales, el gobierno de Vidal aprobó sus decretos de estructura con un diseño heurístico sencillo y un Anexo, que se replica, con los remplazos identificando Unidad de Origen, Dependencia de Origen y Modificación de denominación o Supresión. Consultada sobre la estrategia del Ejecutivo en el diseño y el control de los proyectos de estructuras, la entonces Directora de Planificación y Desarrollo del Empleo Público, dependiente de la Dirección Provincial de Planificación y Gestión Estratégica del Capital Humano-Subsecretaría de Capital Humano, señaló que

... es sabido y conocido que esta gestión se preocupó por ser racional al respecto, con lo cual se preocupó por no agrandar demasiado lo que fue en principio la estructura a nivel macro...

Entrevista a Melina Landea, 28 de noviembre 2019)

Consultada por los diversos criterios que podría tener el análisis de las estructuras por parte de esa Dirección aclaró que el tema de las estructuras "suele ser bien atravesado por las tres patas, la política, la presupuestaria y la técnica, con lo cual siempre es un equilibrio"; respecto a la inexistencia de una norma o parámetro sobre el cual efectuar las recomendaciones dada la derogación del Decreto $N^{\circ}$ 1.322/05 afirmó que

nosotros hoy nos guiamos por criterios racionalistas, yo cada vez que veo una estructura analizo que realmente sea necesaria el área que se está creando, pido información adicional de porqué estás queriendo crear algo, que actividades, que tarea, que personal, que presupuesto tenés disponible para hacerlo, y ahí me fijo si tiene viabilidad que el cargo se cree o no se cree (íd.)

Para estudiar cómo el discurso sobre el sobredimensionamiento del Estado se trasladó a la estructura orgánica de los cargos de la alta gerencia pública hemos seleccionado a los Ministerios de Infraestructura y Servicios Públicos, de Gobierno, de Coordinación y Gestión Pública y de Jefatura de Gabinete de Ministros, tomado como base 0 el final de la gestión de Daniel Scioli, gobernador durante dos periodos, de 2007 a 2015. ${ }^{18}$ Señalamos más arriba que los tres primeros corresponden a la primera Ley de Ministerios; el Ministerio de Coordinación y Gestión Pública tuvo su estructura por Decreto No 39B/2015. Para el Ministerio de Infraestructura y Servicios Públicos, el primer Decreto de la gestión Vidal que aprobó su estructura orgánico funcional fue el $\mathrm{N}^{\circ} 40 \mathrm{~B} / 2015$. Por último, el caso del Ministerio de Gobierno, que aprobó su estructura orgánico funcional con el Decreto $\mathrm{N}^{\circ} 50 \mathrm{~B} / 2015$. 
Con el cambio de Roberto Gigante a Infraestructura y la pretensión de darle más volumen a la alianza llevando al Ministerio de Gobierno a un extrapartidario de origen territorial en del peronismo, ${ }^{19}$ Joaquín De la Torre, se recreó el Ministerio de Jefatura de Gabinete de Ministros, que ya existía al final del mandato de Scioli. Teniendo en cuenta que las funciones son similares a las del disuelto Ministerio de Coordinación y Gestión Pública estos ministerios serán analizados en conjunto.

Lo primero que llama la atención es la alta volatilidad de las estructuras: cinco cambios para el Ministerio de Infraestructura y Servicios Públicos; cinco para el de Gobierno, cuatro para Coordinación y Gestión Pública y para Jefatura de Gabinete de Ministros.

Con excepción del Ministerio de Coordinación y Gestión Pública, luego Ministerio de Jefatura de Gabinete de Ministros, el crecimiento de los cargos en los Ministerios seleccionados fue importante, pero con particularidades. La comparación entre los finales de las gestiones Scioli y Vidal arroja un crecimiento cerca del 30\% en el Ministerio de Infraestructura y Servicios y de poco más del 45\% para el Ministerio de Gobierno, pero cuando analizamos qué cargos son los que más aumentan, resaltan las diferencias. En el caso de Infraestructura y Servicios los cargos que más crecen en el período son los más altos, esto es, las Subsecretarías (66\%); en cambio en el Ministerio de Gobierno se da en las Direcciones que crecieron más del 70\% entre una gestión y otra.

El caso del Ministerio de Jefatura de Gabinete de Ministros es una excepción al crecimiento de cargos políticos, ya que, entre el fin de la gestión de Scioli y fin de la gestión de Vidal se advierte una disminución del $24 \%$ de los cargos. Sin embargo, este resultado debe relativizarse pues el Ministerio de Jefatura de Gabinete de Ministros del final de la gestión de Scioli fue un "superministerio" con más funciones que las de coordinación durante la gestión de Vidal. ${ }^{20}$

Otro dato saliente es el pico del crecimiento de cargos, que se da durante el año de la elección de medio término, coincidiendo con el ya clásico estudio de Oszlak (2003), como puede verse en el siguiente gráfico. 


\section{Evolución de Subsecretarías, Direcciones Provinciales y Direcciones de línea 2015-2019 Provincia de Buenos Aires}

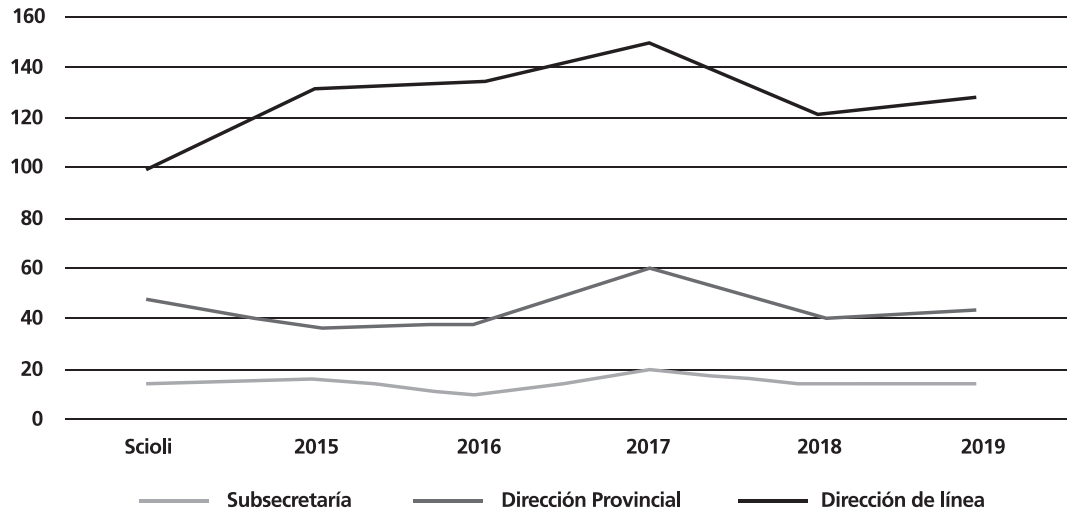

Fuente: Elaboración propia sobre los Ministerios de Coordinación y Gestión Pública, luego Ministerio de Jefatura de Gabinete de Ministros, Ministerio de Infraestructura y Servicios y Ministerio de Gobierno.

Nota: La modificación del Ministerio de Gobierno de diciembre de 2018 se tomó como 2019.

En el conjunto de ministerios seleccionado, respecto de la gestión Scioli los cargos de Subsecretario habían crecido en 2017 poco más del 35\%, los de Directores Provinciales casi un tercio y el $50 \%$ en las direcciones simples.

Por último, en lo que refiere al supuesto criterio de racionalidad técnica en la evaluación de las estructuras de los ministerios seleccionados, no se advierte una regla clara en cuanto a las aperturas que se derivan de las Subsecretarías en las Direcciones Provinciales y de éstas en las direcciones de línea. En efecto, en el conjunto de los Ministerios se advierte que el promedio de las Subsecretarías respecto a las Direcciones Provinciales y de éstas respecto a las de línea sigue la regla de 3, pero con desvíos de 3,8 a 2,3 aperturas por cada línea superior.

\section{Reflexiones finales}

El tamaño del Estado es un asunto de las funciones que este desempeña. Es necesario discutir en forma previa qué tipo de Estado queremos (y consecuentemente, qué funciones tiene) pues el crecimiento/disminución de las estructuras es una consecuencia natural de la ampliación de las funciones estatales y de las demandas que se le formulan. Esta discusión es de naturaleza política, pues sólo podremos ajustar el tamaño luego de haber consensuado los fines.

Cambiemos hizo del tamaño del Estado un tema en sí mismo, en particular en la provincia de Buenos Aires. En la gestión provincial de Cambiemos en el período analizado hemos detectado un fuerte discurso en torno a la crisis del Estado, la ineficiencia de sus 
burocracias, la opacidad de su desempeño y las prebendas. Cambiemos entendió al Estado como una compleja red de estructuras burocráticas superpuestas, organismos sin funciones claras u obsoletos, controles ineficientes y baja productividad. En el ámbito de la Provincia de Buenos Aires, fue la propia Gobernadora, y excepcionalmente el Ministro Salvai, quienes lideraron los discursos acerca de la reforma del Estado y la Administración bonaerense.

Hemos identificado una clara línea argumental en torno a la necesidad de reducir los gastos de la política. Las críticas de Cambiemos han ponderado la necesidad de reducir las estructuras estatales, no ya para dotarlo de un aparato más ágil, como se justificara en los años '90, sino para "resolver problemas concretos de los vecinos" desarticulando así concepciones, como el bienestar general, y la de ciudanía como categoría igualadora.

La supuesta racionalidad técnica en el diseño de las estructuras, derogado el Decreto $\mathrm{N}^{\circ}$ 1.322/05, no fue sino libertad en el diseño y su aprobación, explicitando la politicidad de esta función instrumental del Estado. La lógica racionalizadora pretendió ser un recorte, pero no necesariamente de las estructuras o cargos gerenciales. A pesar del recorte anunciado en la política, la gestión finalizó con más Ministerios y Secretarías que la última Ley de Ministerios de Daniel Scioli.

Para dar cuenta de la cantidad de cargos políticos, será necesario un estudio más amplio y hacer el seguimiento de todos los Ministerios y Secretarías durante los cuatro años de Cambiemos en la provincia, pero los casos identificados en los Ministerios seleccionados son elocuentes. También el Cambiemos bonaerense acrecentó el Estado y no sólo cuantitativamente: habiendo recortado funciones y gastos en pos de las obras concretas, el crecimiento de la cantidad de cargos políticos fue más llamativo.

¿Cuál fue el recorte de Cambiemos en la Provincia? Si no lo fue en la política, sí lo fue en los agentes del Estado, con las políticas de control biométrico, achatamiento de la escala de salarios, retiros anticipados y una crítica reiterada de las formas de labor y conocimientos del empleado público. Tal como se desprende de la comparación del presupuesto de la Administración Pública Provincial 2015 (Ley N 14.652) con el de 2019 (Ley No 15.078), si bien la planta total permanente y transitoria de la Administración Central, descentralizados e instituciones de previsión social aumentó aproximadamente en un $7 \%$ y un $22 \%$ respectivamente, la desagregación de las cifras revela que el gran crecimiento fue en el Ministerio de Seguridad cuya planta permanente creció más del 35\% y en el de Justicia, que incluye el Servicio Penitenciario que aumentó poco más del 10\%, en conjunto, lo cual es una manifestación de la securitización de la política pública. En cambio, en el conjunto de ministerios que estudiamos, la planta permanente pasó en de 5.910 en 2015 a 4.651 en 2019, y la planta temporaria de 6.192 a 529 entre ambos años, lo que representó una disminución conjunta de más del $50 \%$ de los empleados. 
Señalamos al inicio del artículo la imagen de la gestión deVidal como un cuadro dentro de otro cuadro para destacar que su gestión no fue un espejo de las políticas impulsadas desde la Nación. Lejos se encuentraVidal de haber cuestionado los grandes lineamientos dados por el gobierno nacional de Cambiemos, pero a diferencia del Cambiemos nacional, el crecimiento en números de Ministerios no fue exponencial ni los ministros pertenecieron mayoritariamente a una CEOcracia ajena a la política. Cuando el gobierno nacional decidió la disminución del número de ministerios, la provincia tampoco acompañó ese gesto de austeridad, disminuyéndolos.

Otro dato que se advierte es que, a pesar de presentarse como un gobierno distinto, no hubo grandes cambios en los nombres de los Ministerios, lo que en verdad puede dar cuenta de ciertas funciones estables dentro del Estado bonaerense. Es por ello que no puede advertirse un proyecto claro de gobierno provincial de Cambiemos más allá de la crítica al Estado y al empleado provincial como representación de lo burocrático; más bien, hemos destacado la clara incongruencia entre lo dicho (recortar los gastos de la política) y lo hecho (crecimiento de las estructuras).

Continuidades en el crecimiento de la alta gestión pública junto con discursos sobre la necesidad del recorte de la política; criterios irracionales en el diseño las estructuras sin limitaciones normativas, dan lugar a contradicciones insalvables. Cuando se caen los castillos de naipes, nadie sabe cuál fue la falla estructural. 
Anexo 1. Organismos con rango equivalente a Ministerio o Secretaría de Estado al momento final del mandato de Scioli y durante el período de Vidal.

\begin{tabular}{|c|c|c|c|}
\hline $\begin{array}{l}\text { Ley } N^{\circ} 13757 \text { y modif. } \\
\text { (Scioli) }\end{array}$ & Ley $\mathrm{N}^{\circ} 14.803$ & Ley $\mathrm{N}^{\circ} 14.832$ & Ley $\mathrm{N}^{\circ} 14.989$ \\
\hline $\begin{array}{l}\text { 1. Min. de Jefatura de } \\
\text { Gabinete de Ministros }\end{array}$ & $\begin{array}{l}\text { 1. Min. de Coordinación } \\
\text { y Gestión Pública }\end{array}$ & $\begin{array}{l}\text { 1. Min. de Coordinación } \\
\text { y Gestión Pública }\end{array}$ & $\begin{array}{l}\text { 1. Min. de Jefatura de } \\
\text { Gabinete de Ministros }\end{array}$ \\
\hline 3. Min. de Economía & 2. Min. de Economía & 2. Min. de Economía & 2. Min. de Economía \\
\hline 2. Min. de Gobierno & 3. Min. de Gobierno & 3. Min. de Gobierno & 3. Min. de Gobierno \\
\hline 9. Min. de Infraestructura & $\begin{array}{l}\text { 4. Min. de Infraestructura } \\
\text { y Servicios Públicos }\end{array}$ & $\begin{array}{l}\text { 4. Min. de Infraestructura } \\
\text { y Servicios Públicos }\end{array}$ & $\begin{array}{l}\text { 4. Min. de Infraestructura } \\
\text { y Servicios Públicos }\end{array}$ \\
\hline 8. Min. de Salud & 5. Min. de Salud & 5. Min. de Salud & 5. Min. de Salud \\
\hline 5. Min. de Seguridad & 6. Min. de Seguridad & 6. Min. de Seguridad & 6. Min. de Seguridad \\
\hline 4. Min. de Justicia & 7. Min. de Justicia & 7. Min. de Justicia & 7. Min. de Justicia \\
\hline 7. Min. de Asuntos Agrarios & 8. Min. de Asuntos Agrarios & 8. Min. de Asuntos Agrarios & 8. Min. de Agroindustria \\
\hline $\begin{array}{l}\text { 10. Min. de Desarrollo } \\
\text { Social }\end{array}$ & 9. Min. de Desarrollo Social & \begin{tabular}{|l|} 
9. Min. de Desarrollo \\
Social
\end{tabular} & $\begin{array}{l}\text { 9. Min. de Desarrollo } \\
\text { Social }\end{array}$ \\
\hline \multirow[t]{2}{*}{$\begin{array}{l}\text { 6. Min. de la Producción, } \\
\text { Ciencia y Tecnología }\end{array}$} & $\begin{array}{l}\text { 10. Min. de Producción, } \\
\text { Ciencia y Tecnología }\end{array}$ & 10. Min. de Producción & 10. Min. de Producción \\
\hline & & $\begin{array}{l}\text { 11. Min. de Ciencia, } \\
\text { Tecnología e Innovación }\end{array}$ & $\begin{array}{l}\text { 11. Min. de Ciencia, } \\
\text { Tecnología e Innovación }\end{array}$ \\
\hline \multirow[t]{3}{*}{ 11. Min. de Trabajo } & 11.Min. de Trabajo & 12. Min. de Trabajo & 12. Min. de Trabajo \\
\hline & & 13. Min. de Gestión Cultural & 13. Min. de Gestión Cultural \\
\hline & & & 14. Min. de Asuntos Públicos \\
\hline Sec. General de la Gobernación & Sec. General & Sec. General & Sec. General \\
\hline $\begin{array}{l}\text { Sec. Legal y Técnica } \\
\text { (Decreto 218/2010) }\end{array}$ & Sec. Legal y Técnica & Sec. Legal y Técnica & Sec. Legal y Técnica \\
\hline \multirow[t]{4}{*}{ Sec. de Derechos Humanos } & Sec. de Derechos Humanos & Sec. de Derechos Humanos & Sec. de Derechos Humanos \\
\hline & Sec. de Cultura & & \\
\hline & Sec. de Comunicación & Sec. de Comunicación & \\
\hline & Sec. de Medios & Sec. de Medios & Sec. de Medios \\
\hline Asesoría Gral. de Gobierno & Asesoría Gral. de Gobierno & Asesoría Gral. de Gobierno & $\begin{array}{l}\text { Asesoría Gral. de } \\
\text { Gobierno (con estructura } \\
\text { y presupuesto dentro de la } \\
\text { Sec. Legal y Técnica) } \\
\end{array}$ \\
\hline \multicolumn{4}{|l|}{ Sec. de Deportes } \\
\hline \multicolumn{4}{|l|}{ Sec. de Turismo } \\
\hline \multicolumn{4}{|l|}{ Sec. de Servicios Públicos } \\
\hline $\begin{array}{l}\text { Org. Prov. Para el } \\
\text { Desarrollo Sostenible }\end{array}$ & & & $\begin{array}{l}\text { Org. Prov. Para el } \\
\text { Desarrollo Sostenible }\end{array}$ \\
\hline \multicolumn{4}{|l|}{$\begin{array}{l}\text { Sec. de Desarrollo Estratégico } \\
\text { (Decreto 1079/2013) }\end{array}$} \\
\hline & & & $\begin{array}{l}\text { Org. Prov. de la Niñez } \\
\text { y Adolescencia }\end{array}$ \\
\hline & & & $\begin{array}{l}\text { Org. Prov. de Integración } \\
\text { Social y Urbana }\end{array}$ \\
\hline $\begin{array}{l}\text { Secretaría de Personal y } \\
\text { Política de Recursos Humanos } \\
\text { (Decreto N 658/2012) }\end{array}$ & & & \\
\hline
\end{tabular}

Nota: Elaboración Propia. En cursiva, los Organismos al final del gobierno de Daniel Scioli. En negrita se identifican los cambios durante el gobierno deVidal. 
Anexo 2. Comparación de la última estructura gestión Scioli en el Ministerio de Infraestructura y Servicios Públicos de la Provincia de Buenos Aires (2012) con las modificaciones de la gestión Vidal

\begin{tabular}{|l|c|c|c|c|c|c|}
\hline & $\begin{array}{c}\text { Gestión } \\
\text { Scioli }\end{array}$ & \multicolumn{5}{|c|}{ Gestión Vidal } \\
\hline & $\begin{array}{c}2012 \\
(\text { Decreto } \\
72 / 12)\end{array}$ & $\begin{array}{c}2015 \\
(\text { Decreto } \\
40 \mathrm{~B} / 15)\end{array}$ & $\begin{array}{c}2016 \\
(\text { Decreto } \\
360 / 16)\end{array}$ & $\begin{array}{c}2017 \\
(\text { Decreto } \\
12 / 17)\end{array}$ & $\begin{array}{c}2018 \\
(\text { Decreto } \\
35 / 18)\end{array}$ & $\begin{array}{c}2019 \\
(\text { Decreto } \\
132 / 19)\end{array}$ \\
\hline Subsecretarías & 3 & 6 & 7 & $\mathbf{9}$ & 5 & 5 \\
\hline $\begin{array}{l}\text { Direcciones } \\
\text { Provinciales }\end{array}$ & 11 & 19 & 19 & $\mathbf{2 7}$ & 13 & 13 \\
\hline $\begin{array}{l}\text { Direcciones } \\
\text { de Línea }\end{array}$ & 29 & 45 & 43 & $\mathbf{5 1}$ & 36 & 37 \\
\hline Total & 43 & 70 & 69 & $\mathbf{8 7}$ & 54 & 55 \\
\hline
\end{tabular}

Nota: Elaboración Propia. En negrita se identifica el máximo crecimiento en la gestión Vidal.

Anexo 3. Comparación de la última estructura gestión Scioli en el Ministerio de Gobierno de la Provincia de Buenos Aires (2014) con las modificaciones de la gestión Vidal

\begin{tabular}{|l|c|c|c|c|c|c|}
\hline & $\begin{array}{c}\text { Gestión } \\
\text { Scioli }\end{array}$ & \multicolumn{5}{|c|}{ Gestión Vidal } \\
\cline { 2 - 7 } & $\begin{array}{c}2014 \\
\text { (Decreto 338) }\end{array}$ & $\begin{array}{c}2015 \\
\text { (Decreto 50B) }\end{array}$ & $\begin{array}{c}2016 \\
\text { (Decreto 1271) }\end{array}$ & $\begin{array}{c}2017 \\
\text { (Decreto 109) }\end{array}$ & $\begin{array}{c}\text { Marzo } \\
\text { de 2018 } \\
\text { (Decreto } \\
169)\end{array}$ & $\begin{array}{c}\text { Dic. de } \\
2018 \\
\text { (Decreto } \\
1668)\end{array}$ \\
\hline Subsecretarías & 5 & 5 & 5 & 7 & 4 & 4 \\
\hline $\begin{array}{l}\text { Direcciones } \\
\text { Provinciales }\end{array}$ & 12 & 14 & 20 & 23 & 13 & 14 \\
\hline Direcciones de Línea & 26 & 46 & 60 & 67 & 42 & 45 \\
\hline Total & 43 & 65 & 85 & 97 & 59 & 63 \\
\hline
\end{tabular}

Nota: Elaboración Propia. En negrita se identifica el máximo crecimiento en la gestión Vidal. 
Anexo 4. Comparación de la última estructura gestión Scioli en el Min. de Jefatura de Gabinete de Ministros de la Prov. de Bs.As (2014) con las modificaciones de la gestión Vidal en Min. Coordinación y Gestión Pública / Min. de Jefatura de Gabinete.

\begin{tabular}{|l|c|c|c|c|c|}
\hline & Gestión Scioli & \multicolumn{4}{|c|}{ Gestión Vidal } \\
\cline { 2 - 6 } & $\begin{array}{c}2014 \\
\text { (Decreto 822) }\end{array}$ & $\begin{array}{c}2015 \\
\text { (Decreto 39B) }\end{array}$ & $\begin{array}{c}2016 \\
\text { (Decreto 1986) }\end{array}$ & $\begin{array}{c}2018 \\
\text { (Decreto 34) }\end{array}$ & $\begin{array}{c}2019 \\
\text { (Decreto 704) }\end{array}$ \\
\hline Subsecretarías & 6 & 5 & 3 & 5 & 5 \\
\hline $\begin{array}{l}\text { Direcciones } \\
\text { Provinciales }\end{array}$ & 24 & 18 & 11 & 16 & 46 \\
\hline $\begin{array}{l}\text { Direcciones de } \\
\text { Línea }\end{array}$ & 59 & 40 & 31 & 43 & 68 \\
\hline Total & 89 & 63 & 45 & 64 & 46 \\
\hline
\end{tabular}

Nota: Elaboración Propia. En negrita se identifica el máximo crecimiento en la gestión Vidal. 
${ }^{1}$ Dejaremos de lado, consecuentemente, a los asesores dada la imposibilidad de obtener información al respecto. En efecto, como veremos por Decreto $N^{\circ} 37 / 15 B$ se derogó el Decreto $N^{\circ} 1322 / 05$ que fijaba, para el Ministro, hasta 4 asesores de gabinete; para los Secretarios de estado y los Subsecretarios un máximo de hasta 3 asesores. Cada uno de ellos, con igual nivel y jerarquía a Director Provincial afectados al asesoramiento, estudios particularizados u otras tareas de apoyo específicas que se le encomienden. Cambiemos, modificó (y liberalizó) esa cantidad ya que el Decreto $\mathrm{N}^{\circ} 1.278 / 16$ sólo determinó una cierta cantidad de módulos para cada nivel (Gobernador/a, Ministro/Secretario y Subsecretario) que podrían ser repartidos a discreción del funcionario siempre que su remuneración no sea igual ni mayor que la determinada para el funcionario al que asiste (conf. art. 113 de la Ley $\left.N^{\circ} 10.430\right)$. En otro estudio (Gil García y Piana 2019) se ha hecho un relevamiento de las principales políticas en materia de empleo público y precarización laboral.

${ }^{2}$ Como puede advertirse de estos estudios, la matriz institucionalista o neoinstitucionalista es el principal eje de sustento teórico. Pese a sus pretendidos supuestos racionales y el valor de las instituciones en la transformación del comportamiento social, como ha señalado Vilas (2002) “... el neoinstitucionalismo asume a la firma de negocios como el paradigma de organización racional, pero a diferencia de aquélla, enfoca a la firma como una estructura de gestión (governance structure, en términos de Williamson) más que como una función de producción. De esta manera la empresa capitalista deviene referente teórico de la racionalidad y eficiencia del desempeño efectivo de cualquier otra organización y, por lo tanto, también del Estado. (...) El neoinstitucionalismo supone la igual capacidad de los individuos para formar instituciones con independencia de su acceso desigual a recursos de poder (económicos, coactivos, simbólicos, o de otra índole). la empresa capitalista deviene referente teórico de la racionalidad y eficiencia del desempeño efectivo de cualquier otra organización y, por lo tanto, también del Estado".

${ }^{3}$ Frente a afirmaciones como estas, ya Oszlak (1999:7) había señalado que "Existe la ilusión de que si se disminuye la cantidad de Secretarías, Subsecretarías, Direcciones o unidades de otro tipo, se habrá conseguido mejorar el funcionamiento del sector público..." y en verdad, el óptimo de una organización no depende de las cantidades de estructuras organizativas cuanto de un diseño armónico entre las funciones deseadas, sus recursos y los aparatos técnicos burocráticos.

${ }^{4}$ Un interesante estudio empírico que desarrolla este concepto puede verse en el trabajo de Canelo, Castellani y Gentile (2018). Por su parte, Perelmiter y Marcalle (2021) explicitan, desde una visión cualitativa, la necesidad de estudiar las prácticas CEOcráticas a partir de las micropolíticas ministeriales tomando como caso de estudio el Ministerio de Desarrollo Social durante la gestión Cambiemos.

${ }^{5}$ En septiembre de 2018 se eliminaron 10 ministerios, dicha reducción fue luego de una fuerte presión para demostrar austeridad fiscal y, en los hechos, los ministerios recortados pasaron a ser Secretarías de Gobierno con igual rango a un ministerio. Más aun, como demuestra el estudio citado, para fines de 2019 el gobierno de Cambiemos había incrementado en 3\% la cantidad de cargos de la Administración Pública Nacional.

${ }^{6}$ El modelo del ejercicio del poder del PRO recrea el tipo de liderazgo de la empresa familiar donde existe poco espacio para la discusión interna y un fuerte personalismo del fundador. Aún cuando sean notas comunes a los partidos gobernantes en Argentina, el problema de la sucesión es tal vez el uno de los grandes desafios de las empresas familiares y del PRO. Para ampliar, véase Vommaro, Morresi y Bellotti (2015) y más recientemente, sobre la estrategia de agregación a la función pública del PRO, Gessaghi, Landau y Luci (2020). ${ }^{7}$ Esta Ley, con un amplio abanico de herramientas, sólo abrió paso a los diversos decretos y resoluciones que han implantado la obligatoriedad del GDEBA (Piana 2017). Ese mismo mes, a través del Decreto $\mathrm{N}^{\circ} 805 / 16$, se anunció la creación de un portal de datos abiertos para el Estado bonaerense a los efectos de sintetizar la información de los distintos organismos de gobierno.

${ }^{8}$ En lo institucional se creó la Oficina de Fortalecimiento Institucional (OFI) cuyo principal objetivo radicó en la concreción de los objetivos de transparencia, eficacia y transformación de la Administración Pública, en sintonía con las acciones del gobierno nacional.

${ }^{9}$ Agrega Gil García (2017) que la aplicación por la Ley de emergencia de contrataciones en el régimen de trabajador de autónomo permitió la constitución de dos estratos diferenciados de trabajadores contratados: "una cúpula flexibilizada con altas remuneraciones y permeable a los requerimientos del personal político, que tiende a conformar una burocracia paralela, y un sector de trabajadores con funciones y salarios similares al personal de planta permanente y con formas de contratación altamente precarizadas".

${ }^{10}$ Conforme Resolución N ${ }^{\circ}$ 12/19 de la Contaduría General de la Provincia. Para tomar dimensión de la trasferencia de funciones debe tenerse presente que con la vieja Ley de Contabilidad, que incluía el proceso de compras, el Ejecutivo debía aprobar las licitaciones de más de \$15.040.000 (último valor fijado por la Resolución $N^{\circ} 211 / 14$ de la Contaduría General de la Provincia). Al momento de aprobarse por la ley de presupuesto 2017, el valor de la Unidad de Contratación fue fijado en $\$ 30$, lo que traducido en Unidades de Contratación para la vieja ley eran poco más de 500.000 Unidades de Contratación, mientras que con Vidal, ella sólo intervendría en procesos de más de 15.000.000 Unidades de Contratación. Además, en el Decreto N 59/19 también se autorizó a delegar la aprobación de la licitación. 
${ }^{11}$ Sin embargo, la Ley final de Ministerio de la Administración de Daniel Scioli, contaba con igual número de ministerios y secretarías a la nueva ley de Vidal. Véase el texto actualizado de la Ley $\mathrm{N}^{\circ} 13757$ con las modificaciones introducidas por las leyes 13881, 13927, 13929, 13975, 14131, 14199, 14331, 14393, 14453 14542, 14646 y 14652. https://normas.gba.gob.ar/documentos/V9L1IPB.html

${ }^{12}$ Ellos eran los Ministerios de Coordinación y Gestión Pública; de Economía; de Gobierno; de Infraestructura y Servicios Públicos; de Salud; de Seguridad; de Justicia; de Asuntos Agrarios; de Desarrollo Social; de Producción, Ciencia y Tecnología y de Trabajo y, por otro, las Secretarías General; Legal y Técnica; de Derechos Humanos; de Cultura; de Comunicación y de Medios, todas ellas con rango de Ministerio (Ley No 14.803, art. 13).

${ }^{13}$ En nuestro registro esta Dirección no aparece contabilizada debido a su jerarquía constitucional. La denominación obedece a razones históricas.

${ }^{14}$ Ley $\mathrm{N}^{\circ} 13.757$ y modificatorias. https://normas.gba.gob.ar/documentos/V9LplIPB.html

15 https://infocielo.com/nota/66653/los_ministros_de_vidal_uno_a_uno_quienes_son_los_funcionarios_que_ manejaran_la_provincia/.A este núcleo se sumó más tarde, en mayo de 2017 y luego de varios meses de acefalía, el Ministro de Producción, Javier Tiziado en reemplazo de Joaquín De la Torre. Si bien era Tiziado era Subsecretario de Comercio Interior de la Nación, su experiencia previa a este provenía exclusivamente del ámbito privado.

${ }^{16}$ La competencia del Ministerio de Economía de "centralizar, organizar y• coordinar las acciones vinculadas al cobro de los diversos créditos fiscales originados en las distintas áreas y organismos, proponiendo los apoderados al Señor Fiscal de Estado" fue pasada al Ministerio de Gobierno.

${ }^{17}$ La última modificación de la Ley de Ministerios originaria fue a través de la Ley impositiva de 2017, la Ley $\mathrm{N}^{\circ}$ 14.880, promulgada el 28 de diciembre de 2016 y publicada en el Boletín Oficial $\mathrm{N}^{\mathrm{o}} 27.940$ el 2 de enero de 2017, introduciendo cambios menores a las competencias que ya tenía el Ministerio de Gobierno.

${ }^{18} \mathrm{El}$ primer funcionario designado para ejercer como Ministro Secretario en esa área fue Roberto Gigante, designado a través del Decreto $\mathrm{N}^{\circ} 5 \mathrm{~B} / 2015$, hasta su posterior designación como Ministro de Infraestructura y Servicios Públicos, oficializada por el citado Decreto Nº 1983/2016.

${ }^{19}$ Aquí puede señalarse otro contrapunto más con el modelo de Macri, quien sólo con la incorporación final del entonces senador Miguel Pichetto, aunque con carácter individual, pudo dar un poco de aire a su proyecto de reelección.

${ }^{20} \mathrm{El}$ recorte de cargos en el Ministerio de Jefatura de Gabinete parece ser más bien una decisión hacia adentro del Ministerio que una decisión transversal ya que el ministro refrendó todos los decretos de crecimiento de estructuras. 


\section{Referencias Bibliográficas}

Anria, Santiago y Vommaro, Gabriel (2020) "En Argentina, un "giro a la derecha" que no fue y el improbable regreso del peronismo de centro-izquierda" en Más poder local, $\mathrm{N}^{\circ}$ 40:6-10.

Astarita, Martín (2018) "Cambiemos y su modelo de Estado: Hacia un orden jerárquico y modernizador”. En Daniel García Delgado, Cristina Ruiz del Ferrier y Beatriz de Anchorena (comps.) Elites y captura del Estado: control y regulación en el neoliberalismo tardío. Buenos Aires, Flacso Argentina:61-90.

Badía, Gustavo y Martina Saudino (2019) "La reforma administrativa en la provincia de Buenos Aires (2015-2018): una primera aproximación”. Ec-Revista de Administración y Economía, II, 3:33-59.

Bernazza, Claudia (2019) "Proyecto neoliberal y resistencia estatal. Tensiones y conflictos en el escenario de la Administración Pública”. En Daniel García Delgado y Cristina Ruiz del Ferrier (comps.) En torno al rumbo: pensamiento estratégico en un tiempo de oportunidad. Buenos Aires: Flacso Argentina:85-100.

Bernazza, Claudia y Gustavo Longo (2014) "Debates sobre capacidades estatales en la Argentina. Un estado del arte". Revista Estado y Políticas Públicas, 3:107-130.

Bertranou, Julián (2013) “Capacidad estatal: aportes al debate conceptual”. Ponencia presentada en el Séptimo Congreso Argentino de Administración Pública, Mendoza, 18,19 y 20 de septiembre.

Canelo, Paula, Castellani, Ana y Gentile, Julia (2018) "Articulación entre elites económicas y elites políticas en el gabinete nacional de Mauricio Macri (2015-2018)" En Daniel García Delgado, Cristina Ruiz del Ferrier y Beatriz de Anchorena (comps.) Elites y captura del Estado: control y regulación en el neoliberalismo tardío. Buenos Aires: Flacso Argentina. 117-135.

Canelo, Paula (2019) ¿Cambiamos? La batalla cultural por el sentido común de los argentinos. Buenos Aires: Siglo XXI,

Camou, Antonio y Sebastián Mateo (2007) “¿El tiempo vence a la organización? Dinámica política, estructuras estatales y políticas sociales en la Provincia de Buenos Aires (1984-2004)". Cuestiones de Sociología, 4:129-142. 
Cao, Horacio, Arturo Laguado Duca y Maximiliano Rey (2018) "El homo corporativo: Las elites estatales en el neoliberalismo tardío”. En Daniel García Delgado, Cristina Ruiz del Ferrier y Beatriz de Anchorena (comps.) Elites y captura del Estado: control y regulación en el neoliberalismo tardío. Buenos Aires: Flacso Argentina,:137-156.

El Cronista (2018) "Junto aVidal, Macri defendió la reducción de cargos en el Estado". El Cronista, 1/02/18. Recuperado el 12 de abril de 2020 en https://www.cronista. com/economiapolitica/Junto-a-Vidal-Macri-defendio-la-reduccion-de-cargos-en-elEstado-20180201-0083.html

El Patagónico (2017) "María Eugenia Vidal envía proyecto para reducir 221 cargos". Portal El Patagónico. 12/12/17. Recuperado el 12 de abril de 2020 en https://www. elpatagonico.com/maria-eugenia-vidal-envia-proyecto-reducir-221-cargos-n3053267.

Fiscante, Leonardo Miguel y Ricardo Sebastián Pianan (2018) "Procesos de reforma en los Organismos de Control. El caso del Registro de Proveedores de la Contaduría General de la Provincia de Buenos Aires”. Estudios Sociales del Estado 4 (7):214-242.

García Delgado, Daniel (2017) “Modernización y reforma del Estado en el Neoliberalismo tardío”. En Daniel García Delgado y Agustina Gradin (comps.) Documento de trabajo No 5: el neoliberalismo tardío: teoría y praxis. Buenos Aires: Flacso Argentina:93-108.

García Delgado, Daniel (2019) "Un rumbo distinto es posible. Seis políticas estratégicas y un Nuevo Contrato Social”. En Daniel García Delgado y Cristina Ruiz del Ferrier Cristina (comps.) En torno al rumbo: pensamiento estratégico en un tiempo de oportunidad. Buenos Aires: Flacso Argentina:29-54.

García Delgado, Daniel (2020) Estado, sociedad y pandemia: ya nada va a ser igual. Buenos Aires: Flacso Argentina.

García Delgado, Daniel y Agustina Gradin (2017) “Neoliberalismo tardío: Entre la hegemonía y la inviabilidad. El cambio de ciclo en la Argentina”. En Daniel García Delgado y Agustina Gradin (comps.) Documento de trabajo No 5: el neoliberalismo tardío: teoría y praxis. Buenos Aires: Flacso Argentina:15-26.

Gasparin, José, Jimena Rubio, Lucía Aruanno y Gonzalo Diéguez (2020) “GPS del Estado. Radiografía y balance de la Administración Pública Nacional 2015-2019”. Disponible en https://www.cippec.org/wp-content/uploads/2020/03/219-DPP-GPGPS-del-Estado.-Gasparin-Rubio-Aruanno-y-Dieguez-enero-2020.pdf accesado el 12 de abril de 2020 . 
Gessaghi,Victoria, Landau Matías y Luci, Florencia (2020) "Clase alta, empresa y función pública en Argentina” en Revista Mexicana de Sociología 82, núm. 2 (abril-junio, 2020): 403-428.

Gil García, Magdalena y Ricardo Sebastián Piana (2019) "Historia reciente del empleo público del gobierno de Cambiemos en la provincia de Buenos Aires (20152018). Su estudio a partir de sus dimensiones normativas, discursivas y operativas". Historia Regional. 40:1-17. http://historiaregional.org/ojs/index.php/historiaregional/ index accesado el 12 de abril de 2020.

Gil García, Magdalena (2017) "Políticas de empleo público en la provincia de Buenos Aires (1991-2016)". Revista Perspectivas de Políticas Públicas 13:139-160.

Gobierno de la Provincia de Buenos Aires (2019) (01 de marzo de 2019). En vivo: la Gobernadora Vidal en la apertura de la Asamblea Legislativa. 1 de marzo. Youtube. https:// www.youtube.com/watch? $=c R u K d W 11 B v o$

Guyot, Carlos, Claudio Jacquelin y José Del Río (2015) "Vidal: "Hay que reducir el gasto político en la provincia”". La Nación, 13 de diciembre en https://www. lanacion.com.ar/politica/maria-eugenia-vidal-hay-que-reducir-el-gasto-politico-enla-provincia-nid1853817. Recuperado el 12 de abril de 2020.

Han, Byul-Chul (2014) Psicopolítica: Neoliberalismo y nuevas técnicas de poder.Barcelona:Herder.

Infocielo (2015) "Los ministros de Vidal: Uno a uno, quiénes son los funcionarios que manejarán la Provincia”. Portal Infocielo. 11de diciembre. en /https://infocielo.com/ nota/66653/los_ministros_de_vidal_uno_a_uno_quienes_son_los_funcionarios_que_ manejaran_la_provincia/ Recuperado el 12 de abril de 2020.

La Tecla (2017) “El tijeretazo: 221 cargos políticos menos, secretarías que cambian y fin a las jubilaciones de privilegio". En https://www.latecla.info/5/87457-el-tijeretazo221-cargos-polticos-menos-secretarias-que-. Recuperado el 12/4/2020.

Mayntz, Renate (1985) Sociología de la Administración Pública. Madrid:Alianza Editorial.

Oszlak, Oscar, "La profesionalización del servicio civil en América Latina: impactos sobre el proceso de democratización". Trabajo elaborado en el marco del Proyecto OEA-PNUD, La Democracia de ciudadanía: una agenda para la construcción de ciudadanía en América Latina. 
Oszlak, Oscar (1999) "Quemar las naves (o cómo lograr reformas estatales irreversibles)", Aportes para el Estado y la Administración Gubernamental, 6,(14) 1-28. http://www.oscaroszlak.org.ar/images/articulos-espanol/Quemar\%20las\%20naves.pdf accesado el 12/4/2020.

Perfil (2017) “Los recortes y ajustes llegaron al propio Gobierno". Perfil, 4/12. https:// www.perfil.com/noticias/politica/los-recortes-llegaron-al-propio-gobierno.phtml accesado el 12/4/2020.

Perelmiter, Luisina y Marcalle Malena (2021) “Élites estatales y gestión social en la Argentina de Cambiemos" en Revista Mexicana de Sociología 83, núm. 1 (enero-marzo, 2021): 185-213. http://revistamexicanadesociologia.unam.mx/index.php/rms/article/ view/60027/53121 accesado el 20/12/2020.

Piana, Ricardo Sebastián (2017) "El Plan Estratégico de Modernización de la Administración Pública bonaerense. Un Análisis de los principios, los presupuestos y los modelos". Revista Perspectivas de Políticas Públicas, 12:245-274.

Repetto, Fabián (2004) Capacidad estatal: requisito necesario para una mejor política social en América Latina. Washington, D.C., Instituto Interamericano para el Desarrollo Social (INDES), Documento de Trabajo I-52, https://publications.iadb.org/publications/ spanish/document/Capacidad-Estatal-Requisito-para-el-Mejoramiento-de-laPol\%C3\%ADtica-Social-en-Am\%C3\%A9rica-Latina.pdf accesado el 5/6/2020.

Tamayo Sáez, Manuel (1997) “El Análisis de las Políticas Públicas”. En Rafael Bañón y Ernesto Carrillo (comps.). La Nueva Administración Pública. Madrid: Alianza Universidad, págs. 281-312.

Televisión Pública (2015) Visión 7 - María Eugenia Vidal asumió como Gobernadora. 10/12/2015 Youtube. https://www.youtube.com/watch?v=2VdNeAFpSeA. Accesado el 12/4/2020.

Thwaites Rey, Mabel (2005) “Tecnócratas vs. Punteros. Nueva falacia de una vieja dicotomía: política vs administración”. En:Thwaites Rey, Mabel y Andrea López, (eds.) Entre tecnócratas globalizados y políticos clientelistas: derrotero del ajuste neoliberal en el Estado argentino. Buenos Aires, Prometeo, págs 91-116.

Vilas, Carlos M. (1997) "La reforma del Estado como cuestión política". Revista Política y Cultura, 8:147-185. 
Vilas, Carlos M. (2002) "La piedra en el zapato. Estado, instituciones públicas y mercado”. En L. Campos Aragón (coord.). La realidad económica actual y las corrientes teóricas de su interpretación. Ciudad de México: UNAM, Instituto de Investigaciones Económicas/Miguel Ángel Porrúa: 13-39. http://cmvilas.com.ar/attachments/ article/83/LA\%20PIEDRA\%20EN\%20EL\%20ZAPATO.pdf accesado el 12/4/2020.

Vommaro, Gabriel, Morresi, Sergio y Bellotti, Alejandro (2015). Mundo PRO: anatomía de un partido fabricado para ganar. Buenos Aires: Planeta.

\section{Sitios Web consultados}

Youtube C5N. (01 de marzo de 2016). C5N - Política: María Eugenia Vidal abrió el año legislativo. Youtube. https://www.youtube.com/watch?v=GmbCKVIVA0A.

Youtube C5N (2018) María Eugenia Vidal abrió las sesiones de la Legislatura Bonaerense. Youtube. 1 de marzo https://www.youtube.com/watch?v=T7wIA6Ckef8.

Youtube Gobierno de la Provincia de Buenos Aires. (2019) En vivo - la Gobernadora Vidal en la apertura de la Asamblea Legislativa 2019. Youtube. 1 de marzo https://www. youtube. $\mathrm{com} /$ watch? $\mathrm{v}=\mathrm{cRuKdW} 11 \mathrm{Bvo}$

\section{Cómo citar este artículo:}

Piana, Ricardo Sebastián y Daniel José Patiño Jaramillo (2021) “Las estructuras organizativas en la Provincia de Buenos Aires durante el gobierno de Cambiemos (20152019. Estudio de caso". Revista Perspectivas de Políticas Públicas vol. 10 No 20:299-327 